\title{
Diagnostic Accuracy of IS6110 Insertion Gene, Hsp65, and Xpert MTB/RIF for Rapid Diagnosis of Pulmonary Tuberculosis
}

\author{
Aymen Awad Abdelhaleem ${ }^{1,2 *}$, Almonther Abdallah Hershan ${ }^{1,3}$, Pradeep Kumar Agarwal ${ }^{4}$ \\ ${ }^{1}$ Endemic and Tropical Diseases Unit, Medical Research Center, Jazan University, Jazan, Saudi Arabia \\ ${ }^{2}$ Faculty of Medical Laboratory Sciences, Alneelain University, Khartoum, Sudan \\ ${ }^{3}$ Faculty of Medicine, Jazan University, Jazan, Saudi Arabia \\ ${ }^{4}$ Jazan Chest Disorders Hospital, Jazan, Saudi Arabia \\ Email: *aabdelhaleem@hotmail.com, *aabdelhaleem@jazanu.edu.sa
}

How to cite this paper: Abdelhaleem, A.A., Hershan, A.A. and Agarwal, P.K. (2017) Diagnostic Accuracy of IS6110 Insertion Gene, Hsp65, and Xpert MTB/RIF for Rapid Diagnosis of Pulmonary Tuberculosis. Journal of Tuberculosis Research, 5, 1-12.

https://doi.org/10.4236/jtr.2017.51001

Received: January 8, 2017

Accepted: February 5, 2017

Published: February 8, 2017

Copyright ( 92017 by authors and Scientific Research Publishing Inc. This work is licensed under the Creative Commons Attribution International License (CC BY 4.0).

http://creativecommons.org/licenses/by/4.0/

\begin{abstract}
Purpose: To evaluate diagnostic accuracy of IS6110 insertion genes, $h s p 65$, and Xpert MTB/RIF for rapid diagnosis of pulmonary tuberculosis. Methods: Sixty patients, medically reported HIV negative, clinically suspected of having pulmonary tuberculosis, were included in this study, and consented before enrolment. Sputum samples were gathered once, and tested by smear for Acid Fast Bacilli (AFB). Cultured in the Loewenstein-Jensen (LJ) medium for $M$. tuberculosis growth, $M$. tuberculosis DNA was detected by conventional PCR targeting IS6110, and $h s p 65$ genes using specific primers, and automated nested real-time PCR targeting $r p o B$ gene. Sensitivity, specificity and diagnostic accuracy were calculated for each method compared to culture. Results: Compared with culture as reference method, smear, IS6110, hsp65, and Xpert MTB/RIF had sensitivity $77.14 \%, 100 \%, 100 \%$, and $100 \%$, specificity $92 \%$, $96 \%, 96 \%$, and $96.97 \%$, and diagnostic accuracy $83.33 \%, 98.33 \%, 98.33 \%$ and $98.21 \%$ respectively. Molecular diagnostic methods had the highest diagnostic accuracy, whereas smear had the lowest. No statistical significance, ( $p$ value $>$ 0.05 ) was detected between the patients' demographic data and the presence or absence of TB infection. Conclusion: The diagnostic accuracy that we got from the molecular methods, confirmed the diagnostic value of molecular detection of $M$. tuberculosis in pulmonary cases, supporting the application of automated and conventional PCR in rapid analysis. Smear could be more efficient when used for treatment monitoring. Combination between one-molecular techniques with smear as a routine method could be valid for rapid diagnosis of TB.
\end{abstract}

\section{Keywords}

Rapid Diagnosis, Pulmonary TB, Molecular Tests 


\section{Introduction}

Tuberculosis (TB) is known to be a worldwide health issue. It has been recorded to influence more than 12 million individuals every year, and the vast majority of the cases are connected with the Human Immune deficiency Virus (HIV) as TB/HIV co-infection, which builds mortality rate [1]. Tuberculosis is an airborne ailment brought by the bacteria known as Mycobacterium tuberculosis [1].

In recent years, there is an increased TB incidence in Saudi Arabia. Several predisposing factors such as the high economic living in Saudi Arabia, attract many workers from affected areas, and also the frequent visit of pilgrims to the holy cities [2] [3] [4].

The detection of TB bacteria in sputum smear (Acid-fast bacilli smear) still remains one of the good choices of diagnosis especially in rural areas, and lowincome countries. Though, a few nations use sputum smear for treatment observing instead of analytic purpose. Culture method (the current reference standard) is used in countries with good laboratory infrastructure. Recently, the frequent use of molecular methods to diagnose tuberculosis has raised hopes for the early detection of the disease [1].

Diverse gene targets like IS6110, 16S $r D N A, r p o B$, recA, and hsp65, which are used to distinguish $M$. tuberculosis gene in sputum tests, has demonstrated variability in affectability and specificity. IS6110 is a standout amongst the most well-known genes effectively used to recognize and distinguish $M$. tuberculosis DNA in clinical specimens by PCR [5] [6] [7] [8]. The gene demonstrated variability in affectability and specificity as indicated by the kind of tests, of the TB restriction in the body, and nearness or nonappearance of TB/HIV co-infection [6]-[12]. Likewise, the quality encoding $65-\mathrm{kDa}$ heat stun protein (hsp65) has been accounted as a valuable focus for mycobacterium discovery by PCR- based methods [13].

A new rapid technology such as Xpert MTB/RIF detects DNA of $M$. tuberculosis and rifampicin resistance gene by Real Time-PCR [14] [15]. It is an automated Nucleic Acid Amplification Tests (NAAT), which isolates and detects $M$. tuberculosis in raw materials or sediment of sputum specimens, simultaneously. It detects most of the relevant rifampicin resistance and mutant genes. Besides, Xpert MTB/RIF required a very little technical training, and results were obtained within 90 minutes from raw sputum samples [16].

In our study, we evaluated the conventional PCR targeting IS6110, and hsp65 ( TB11/12) genes, and automated nested real-time PCR targeting rpoB gene to recognize $M$. tuberculosis DNA among suspected TB patients.

\section{Materials \& Methods}

\subsection{Ethical Approval}

This study was ethically approved by the Jazan University standing committee for biomedical research ethics (SCBRE) with approval Ref No. 2198/60. 


\subsection{Patients}

Sixty patients who are reported HIV negative, clinically suspected of having pulmonary tuberculosis, attended to the chest diseases hospital Laboratory at the Jazan area south-west Saudi Arabia, were included in this study, were as patients whom started treatment were excluded from this study. All included patients consented before enrollment in the study.

\subsection{Samples Collection and Preparation}

Sixty sputum tests were gathered, and prepared by standard research facility methods. For cleaning and processing, we took after the method portrayed by (Kent and Kubica, 1985) [17]. Briefly about $3 \mathrm{ml}$ of sputum sample was added to an equal volume of BBL Myco Prep (cat\#240862) containing NALC-NaoH with PBS in $15 \mathrm{ml}$ falcon tube (BD), kept for 15 minutes for digestion, and then PBS was added till $15 \mathrm{ml}$, centrifuged at $3000 / \mathrm{rpm} 4^{\circ} \mathrm{C}$, for 15 minutes, and the supernatant was discharged and $3 \mathrm{ml}$ PBS was added to the pelted sample for DNA extraction and detection assays. Smears and cultures were performed before sample deactivation. The sample deactivation as described by Doig et al. 2002 [18], was done for the sample before transferring to a molecular biology lab for PCR.

\subsection{Ziehl Neelsen (ZN) Staining Method}

Sputum tests were researched for the nearness of acid-fast bacilli (AFB) by Ziehl Neelsen staining method, smear arrangement and staining was done by maker's guideline of Crescent Ref MS412, and Lot number 32706F.

\subsection{Culture}

About $0.5 \mathrm{ml}$ of all sputum samples was cultured in the Loewenstein-Jensen (LJ) medium. Liquid culture was not used in this study because it was not available at the time when we did the study. A negative culture was affirmed following 8 weeks of incubation, and a positive culture was affirmed by the typical growth development of M. tuberculosis trailed by AFB smear and Real-time PCR discovery. The positive control strain of Mycobacterium species was generously provided by the laboratories of the microbiology department of the faculty of medicine King Khalid University.

\subsection{DNA Extraction}

DNA was extracted from sputum, and a positive culture By Promega DNA extraction kit according to the manufacturer's instruction with minor modifications, as lyses step sputum samples and purified culture was treated with a $20 \mathrm{ul}$ freshly prepared lysosyme solution(Cat\#L6876, Sigma, USA) at concentration 10 $\mathrm{mg} / \mathrm{ml}$. The extracted DNA was kept in $-20^{\circ} \mathrm{C}$ till used.

\subsection{Amplification of IS 6110 Gene by PCR}

A $20 \mu \mathrm{L}$ of PCR reaction was prepared by adding $1 \mu \mathrm{L}$ of 10x dNTPs $(1.25 \mu \mathrm{M}$ each of dTTP, dGTP, dCTP, and dATP), $1 \mu \mathrm{L}$ of each primer $(0.5 \mu \mathrm{M}), 4 \mu \mathrm{L}$ of 
$10 \mathrm{~min}$ PCR buffer, $2 \mu \mathrm{L}$ of $\mathrm{MgCl}_{2}(50 \mu \mathrm{M}), 5.8 \mu \mathrm{L}$ of sterile distilled water, $0.2 \mu \mathrm{L}$ of Taq polymerase of ( $5 \mathrm{Unit} / \mu \mathrm{L}$ ), and $5 \mu \mathrm{L}$ DNA sample. DNA was amplified by PCR using the following cycle conditions: $94^{\circ} \mathrm{C}$ for 5 minutes, then 38 cycles: $\left(94^{\circ} \mathrm{C}\right.$ for 1 minute, $68^{\circ} \mathrm{C}$ for 1 minute). The primers of $I S 6110$ genes were (F, 5'-CCT GCG AGC GTA GGC GTC GG-3'; R, 5' CTC GTC CAG CGC CGC TTC GG), which amplified $123 \mathrm{bp}$ fragment as described by [19] [20]. The presence of a single band equivalent to $123 \mathrm{bp}$ (Figure 1) was taken as positive results, while the same band produced by the positive control, and the negative control offered no response.

\subsection{Amplification of $h s p 65$ by PCR}

PCR master mix for $h s p 65$ (TB11/12) gene was prepared by the same method for IS6110 genes with cycle conditions as follows: $95^{\circ} \mathrm{C}$ for 4 minutes, followed by 30 cycles: $\left(95^{\circ} \mathrm{C}\right.$ for 30 seconds, $56^{\circ} \mathrm{C}$ for 1 minute, $72^{\circ} \mathrm{C}$ for 40 seconds), and a final extension of $72^{\circ} \mathrm{C}$ for 7 minutes. The primers of hsp 65 (TB11/12) insertion gene were TB11 (5'-ACC AAC GAT GGT GTG TCC AT), and TB12 (5'-CTT GTC GAA CCG CAT ACC CT), which amplified a $440 \mathrm{bp}$ fragment as described by [21]. The presence of a single band equivalent to $440 \mathrm{bp}$ (Figure 2) was taken as positive results while the same band produced by the positive control, and the negative control offered no response.

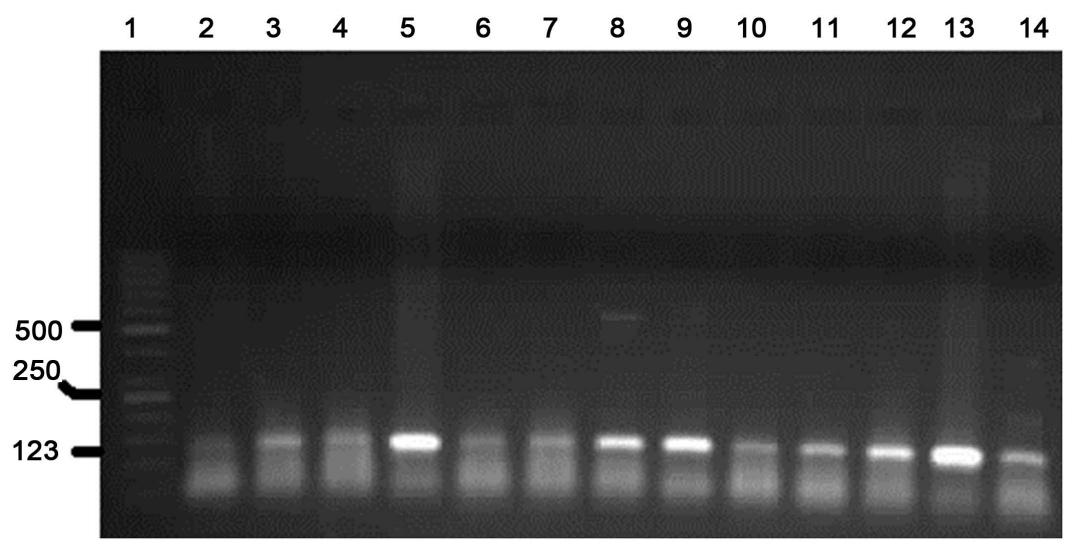

Figure 1. Sputum samples tested by $I S 6110$ gene, lanes1 a $50 \mathrm{pb}$ Mwt marker, Lane2 negative sample, lanes $3,4,5,6,7,8,9,10,11,12,13$, and 14 positive samples produced $123 \mathrm{pb}$.

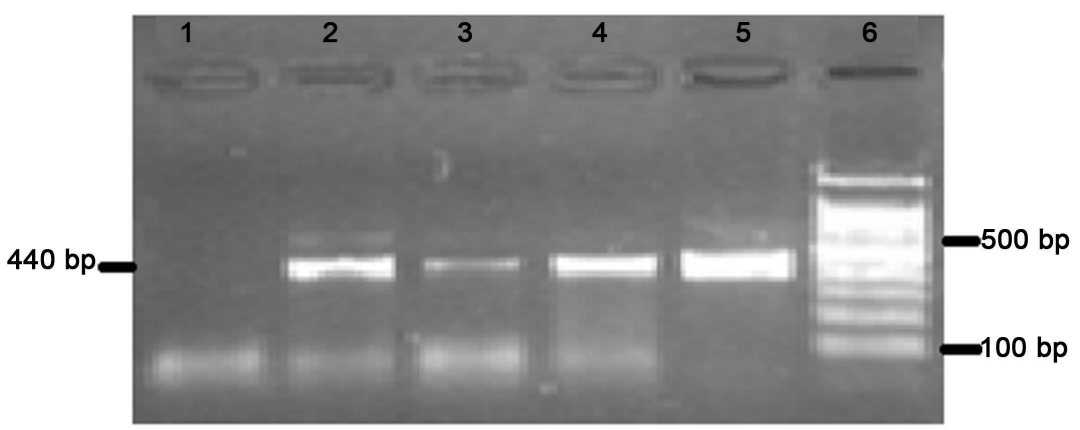

Figure 2. Sputum samples tested by hsp65 (TB11/12) gene, lanes1 negative sample, lanes $2,3,4$, and 5 positive samples produced $440 \mathrm{pb}$, lane 6 a $100 \mathrm{pb}$ marker. 


\subsection{Electrophoresis of Amplified Products}

Amplified products were visualized on $1.8 \%$ agarose gels stained with flouro-safe dye $(0.5 \mathrm{mg} / \mathrm{L})$, and examined under UV light.

\subsection{Xpert MTB/RIF Test}

This test was performed on a robotized Cephoid Gene Xpert Instrument framework (Ref GXMTB/RIF-US-10), quickly, around $0.5 \mathrm{ml}$ of concentrated sputum silt was added to the Gene Xpert cartridge, that holds the Real Time-PCR and PCR reagents and host every one of the procedures. The outcomes were investigated by utilizing Gene Xpert Software adaptation 4.3. The identification of $M$. tuberculosis (MTB) was accounted for when no less than two tests in Ct values inside the substantial extent, and MTB not recognized was accounted for when there was only one or no positive analysis.

\subsection{Statistical Analysis}

Data analysis was directed utilizing (SPSS 20.0 for Windows, SPSS inc. Chicago, IL, USA). The results of the different samples were analyzed and statistically matched. Since the investigation was led utilizing known culture-positive and-negative samples, the greater part of the samples were thought to be true positives (Tps) or true negatives (Tns). The four analyses results were named $\mathrm{Tp}$, false negative ( $\mathrm{Fn}$ ), Tn, or false positive ( $\mathrm{Fp}$ ). The sensitivity and specificity were computed in like manner. Graphic statistics centered on frequency distribution and percentages and Chi-square test was also conducted. A $p$-value $<0.05$ was reflected as statistically significant.

\section{Results}

Sixty TB suspected patients were included in this study, 43 (71.7\%) were male, and $17(23.3 \%)$ were female, 60\% were Saudi nationality, and $40 \%$ were Non Saudi nationality, ages were ranged between 10 - 70 years old, with the majority range between 25 - 44 years (56.7\%), followed by $10-24$ years (26.7\%), and 45 70 years $(16.7 \%)$ as shown in Table 1 . Our results showed no statistical significance, ( $p$ value $>0.05$ ) was detected between the age, sex, and nationality with the presence or absence of TB infection (Table 2).

Out of 60 patients specimens 35 (58.3\%) were positive for MTB, and 25 (41.7\%) were negative for MTB culture (Table 1, Figure 4). Positive M. tuberculosis cultures were affirmed by Real-Time PCR amplification curve, and it created $C t$ values ranged between 11.5 and 25.5 (Figure 3).

Smear results showed that 29 (48.3\%) were AFB positive, and 31 (51.7\%) were non AFB (Table 1, Figure 4). Contrasted with culture as reference method, smear had sensitivity, specificity, positive predictive value (PPV), negative predictive value (NPV), and analytical exactness of $77.14 \%$ (95\% as a confident interval (CI) 60.98, 87.93 ${ }^{1}$ ), 92\% (95\%(CI) 75.03, 97.781), 93.1\% (95\% (CI) 78.04, $98.09^{1}$ ), $74.19 \%$ (95\% (CI) 56.75, 86.3 $)$, 83.33\% (95\% (CI) 71.97, 90.69 ${ }^{1}$ ), respectively as shown in (Table 3 , Figure 5). 


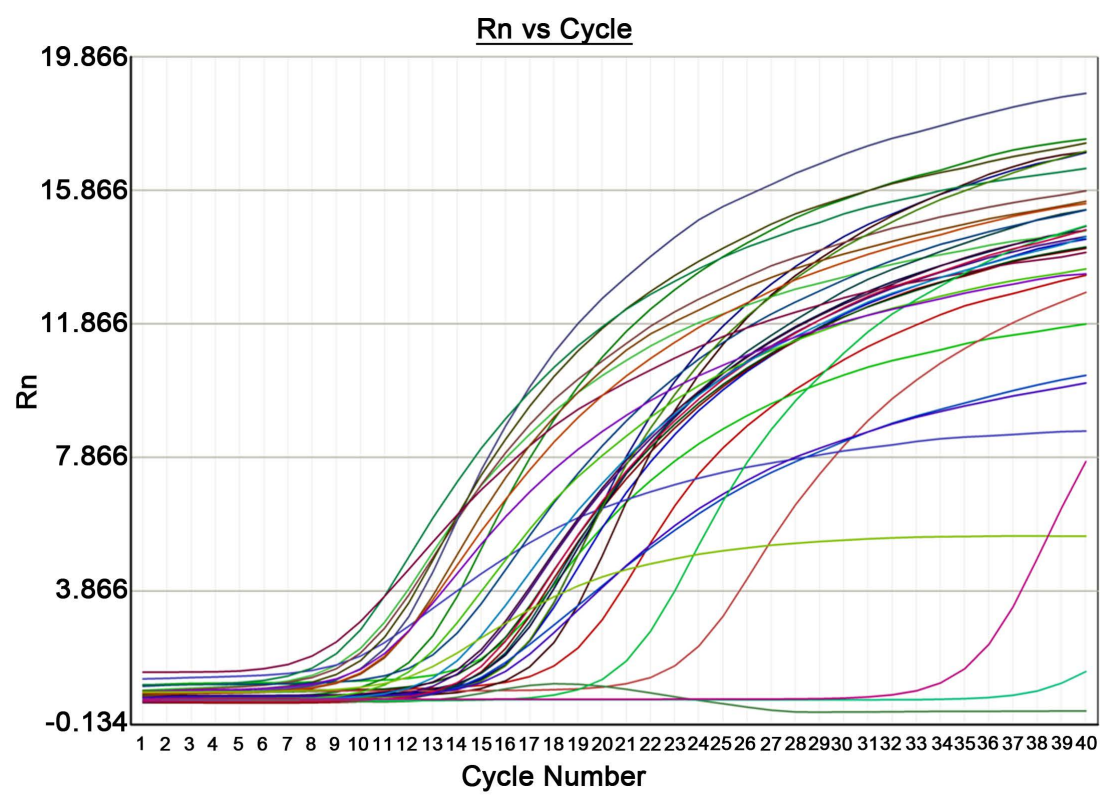

Figure 3. Amplification plot of isolated M. tuberculosis DNA by IS6110 gene, Ct values ranged between 11.5 - 25.5 (Positive control Ct 25.5, Negative control Ct 37.3).

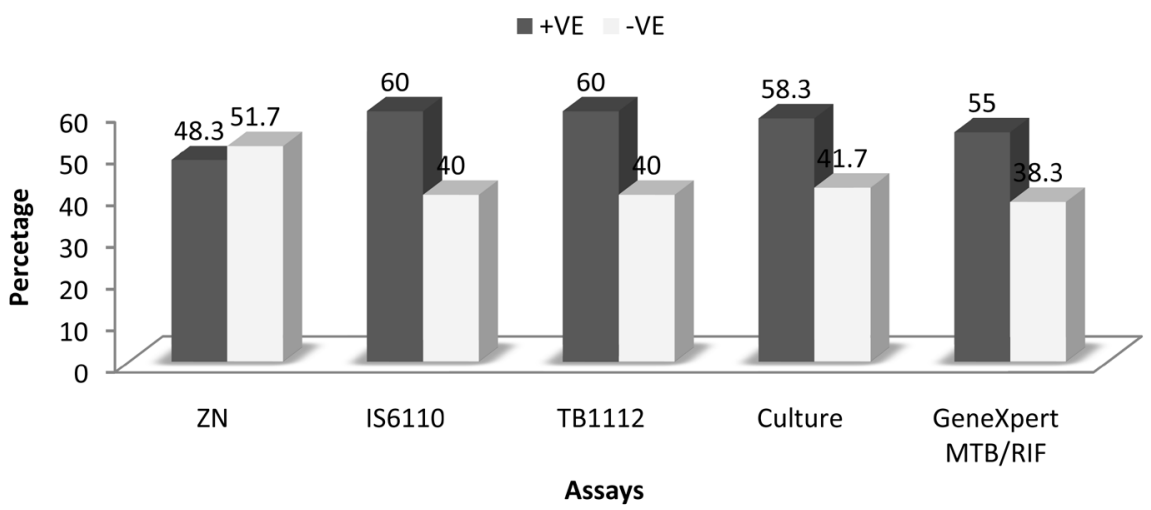

Figure 4. Results of ZN smear, IS6110, TB11/12, GeneXpert MTB/RIF assays and culture method.

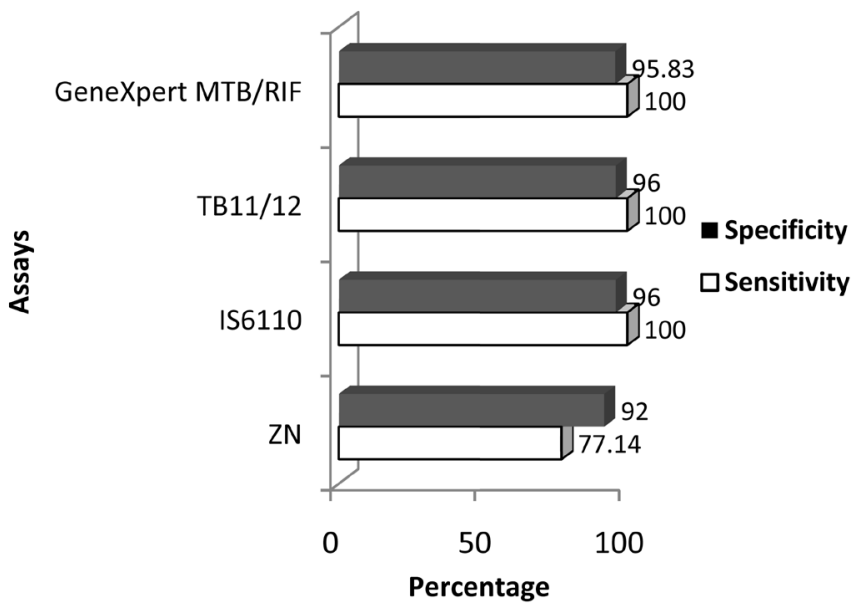

Figure 5. Sensitivity and specificity, of ZN smear, IS6110, TB11/12 and GeneXpert MTB/ RIF assays using culture method as reference. 
Table 1. Characteristics of the 60 patients, specimens analyzed and culture results.

\begin{tabular}{|c|c|c|}
\hline Characteristics & $\mathbf{N}$ & $\%$ \\
\hline \multicolumn{3}{|l|}{ Age groups } \\
\hline $10-24$ years & 16 & 26.7 \\
\hline 25 - 44 years & 34 & 56.7 \\
\hline $45-70$ years & 10 & 16.7 \\
\hline \multicolumn{3}{|l|}{ Gender } \\
\hline Male & 43 & 71.7 \\
\hline Female & 17 & 28.3 \\
\hline \multicolumn{3}{|l|}{ Nationality } \\
\hline Saudi & 36 & 60.0 \\
\hline Non-Saudi & 24 & 40.0 \\
\hline \multicolumn{3}{|l|}{ ZN smear } \\
\hline$+\mathrm{VE}$ & 29 & 48.3 \\
\hline$-\mathrm{VE}$ & 31 & 51.7 \\
\hline \multicolumn{3}{|l|}{ IS6110 } \\
\hline$+\mathrm{VE}$ & 36 & 60.0 \\
\hline$-\mathrm{VE}$ & 24 & 40.0 \\
\hline \multicolumn{3}{|l|}{ TB11/12 } \\
\hline$+\mathrm{VE}$ & 36 & 60.0 \\
\hline$-\mathrm{VE}$ & 24 & 40.0 \\
\hline \multicolumn{3}{|l|}{ Culture } \\
\hline$+\mathrm{VE}$ & 35 & 58.3 \\
\hline$-\mathrm{VE}$ & 25 & 41.7 \\
\hline \multicolumn{3}{|l|}{ Xpert MTB/RIF } \\
\hline$+\mathrm{VE}$ & 33 & 55.0 \\
\hline$-\mathrm{VE}$ & 23 & 38.3 \\
\hline ND & 4 & 6.7 \\
\hline
\end{tabular}

+VE(Positive), - VE(Negative), ND(Not done).

Table 2. Comparison of demographic data of the patients and positive results of $\mathrm{ZN}$ smear, IS6110, TB11/12 and Xpert MTB/RIF assays with the culture method as reference.

\begin{tabular}{cccccc}
\hline \multirow{2}{*}{ Characteristics } & \multicolumn{5}{c}{ NO. and\% of positive samples } \\
\cline { 2 - 6 } & ZN smear & IS6110 & TB11/12 & Xpert MTB/RIF & Culture \\
\hline Age groups & & & & & \\
$10-24$ years & $9(56.2)$ & $10(62.5)$ & $10(62.5)$ & $9(60.0)$ & $10(62.5)$ \\
$25-44$ years & $16(47.1)$ & $21(61.8)$ & $21(61.8)$ & $19(61.3)$ & $21(61.8)$ \\
$45-70$ years & $4(40.0)$ & $5(50.0)$ & $5(50.0)$ & $5(50.0)$ & $4(40.0)$ \\
Gender & & & & & \\
Male & $22(51.2)$ & $27(62.8)$ & $27(62.8)$ & $24(61.5)$ & $27(62.8)$ \\
Female & $7(41.2)$ & $9(52.9)$ & $9(52.9)$ & $9(52.9)$ & $8(47.1)$ \\
Nationality & & & & & $19(54.5)$ \\
Saudi & $15(41.7)$ & $20(55.6)$ & $20(55.6)$ & $15(65.2)$ & $16(66.7)$ \\
Non- Saudi & $14(58.3)$ & $16(66.7)$ & $16(66.7)$ & $15.8)$ \\
Total & $29(48.3)$ & $36(60.0)$ & $36(60.0)$ & $33(58.9)$ & $35(58.3)$ \\
\hline
\end{tabular}

No statistical significance was detected between the specified assay and the culture. 
Table 3. Sensitivity, specificity, positive and negative predictive values, and diagnostic accuracy of the ZN smear, IS6110, TB11/12 and Xpert MTB/RIF assay with the culture method as reference.

\begin{tabular}{cccccc}
\hline \multirow{2}{*}{ Specimen type } & Sensitivity & Specificity & PPV & NPV & $\begin{array}{c}\text { Diagnostic } \\
\text { Accuracy }\end{array}$ \\
\cline { 2 - 5 } & \multicolumn{5}{c}{ No. (\%), 95\% confidence interval (CI) } \\
ZN smear & $77.14 \%$ & $92 \%$ & $93.1 \%$ & $74.19 \%$ & $83.33 \%$ \\
IS6110 & $\left(60.98,87.93^{1}\right)$ & $\left(75.03,97.78^{1}\right)$ & $\left(78.04,98.09^{1}\right)$ & $\left(56.75,86.3^{1}\right)$ & $\left(71.97,90.69^{1}\right)$ \\
& $\left(90.11,100^{1}\right)$ & $\left(80.46,99.29^{1}\right)$ & $\left(85.83,99.51^{1}\right)$ & $\left(86.2,100^{1}\right)$ & $\left(91.14,99.71^{1}\right)$ \\
TB11/12 & $100 \%$ & $96 \%$ & $97.22 \%$ & $100 \%$ & $98.33 \%$ \\
& $\left(90.11,100^{1}\right)$ & $\left(80.46,99.29^{1}\right)$ & $\left(85.83,99.51^{1}\right)$ & $\left(86.2,100^{1}\right)$ & $\left(91.14,99.71^{1}\right)$ \\
Xpert MTB/RIF & $100 \%$ & $96.97 \%$ & $96.97 \%$ & $100 \%$ & $98.21 \%$ \\
& $\left(89.28,100^{1}\right)$ & $\left(79.76,99.26^{1}\right)$ & $\left(84.68,99.46^{1}\right)$ & $\left(85.69,100^{1}\right)$ & $\left(90.55,99.68^{1}\right)$ \\
\hline
\end{tabular}

In the current study, both of $I S 6110$ and Hsp65 (TB11/12) gave similarity in results 36 (60\%) were positive for M. tuberculosis DNA, and 24 (40\%) were negative (Table 1, Figure 5). Compared with culture as reference method, both IS6110 and Hsp65 (TB11/12) genes produced same sensitivity, specificity, positive predictive value (PPV), negative predictive value (NPV), and diagnostic accuracy of $100 \%$ (95\% (CI) 90.11, 100 ${ }^{1}$ ), 96\% (95\% (CI) 80.46, 99.291), $97.22 \%$ (95\% (CI) 85.83, 99.51ํ), 100\% 995\% (CI) 86.2, 100¹), 98.33\% (95\% (CI) 91.14, $99.71^{1}$ ), respectively as shown in (Table 3, Figure 5).

In this study Xpert MTB/RIF showed that 33 (55\%) out of 56 tested samples were positive for MTB, 23 (38.3\%) were negative, and 4 (6.7\%) were not done (ND) for the machine factor, as shown in (Table 1, Figure 4). Compared with culture as reference method, Xpert MTB/RIF gave sensitivity, specificity, positive predictive value (PPV), negative predictive value (NPV), and diagnostic accuracy of $100 \%$ (95\% (CI) 89.28, 100 ${ }^{1}$ ), 96,97\% (95\% (CI) 79.76, 99.26 ${ }^{1}$ ), 96.97\% (95\% (CI) 84.68, 99.46 ${ }^{1}$ ), 100\% (95\% (CI) 85.69, 100¹), 98.21\% (95\% (CI) 90.55, $\left.99.68^{1}\right)$, respectively as shown in (Table 3, Figure 5).

\section{Discussion}

The early diagnosis of TB is very important to start early treatment and to establish preventive measures of the disease control [1]. In this study, the diagnostic accuracy of AFB smear, conventional and automated nested PCR was evaluated compared with culture as a gold standard method.

In this study one patient specimen gave negative result with culture method and positive with molecular methods utilized as a part of this study, this may be due to either by the non-viable bacilli existent in the sample or the small quantity of the bacteria.

When compared with other molecular tests smear produced the lowest sensitivity, which indicated that smear is still not the suitable method for diagnosing $\mathrm{TB}$, although it is a quick and cheap method for diagnosis. On the other hand, 
smear could be more efficient when used for treatment monitoring as described before [1].

Our findings confirm the diagnostic value of $I S 6110$ and $h s p 5$ genes in rapid detection of pulmonary TB, the same findings were mentioned by Ritis et al. (2000) [22] when he used IS6110 gene, although the sources of the samples were different, and of Maccente et al. (2013) [23], when she evaluated the hsp65 gene for rapid diagnosis of TB in a high-burden country. Besides the highest diagnostic accuracy of this method, it has many advantages. Firstly, the method is fast, the results can be obtained within one to two working days. Secondly, the method is cheap, it cost about 7 USD. One patient gave a positive result in this method and a negative result by culture, although this sample statistically was calculated as false positive (FP), it could be the occurrence of non-viable bacilli in this sample.

The Automated Xpert MTB/RIF produced a high diagnostic accuracy for pulmonary $\mathrm{TB}$ in sputum samples, our finding was in strong agreement with a study done by Vinod et al. (2014) [24], although he used samples from Tuberculous meningitis. In our study, one patient sample was positive with Xpert MTP/RIF and negative by culture, the test can detect $M$. tuberculosis DNA from either nonviable or non-intact bacilli [25], taking into account also the culture limitation. Many advantages of the Xpert MTB/RIF are, first, it is fast, the result can be obtained within 90 minutes, second, positive result reflect the true detection of M. tuberculosis rather than nontuberculous mycobacteria [25], third detection of Rifampicin resistant bacteria. Besides all these advantages, the test is expensive, one test cost about 18 USD, which is not suitable for low-income countries.

\section{Conclusion}

Our results and the diagnostic accuracy that we got from the molecular methods, confirm the diagnostic value of molecular detection of $M$. tuberculosis in pulmonary cases, supporting the application of automated and conventional PCR in rapid analysis. Combination between one-molecular techniques with smear as a routine method could be valid for rapid diagnosis of TB.

\section{Limitations}

Culture result itself can be influenced by numerous elements including sample blunders and other mechanical causes can likewise influence culture sensitivity, which demonstrates our study restrictions.

\section{Acknowledgements}

We gratefully acknowledge the Saudi Basic Industries Corporation (SABIC) K.S.A. for supporting this work (Grant No 2000/S2/36), and Deanship of scientific research at Jazan University Saudi Arabia. We also acknowledge the laboratories of Microbiology at Jazan Chest Diseases Hospital, King Fahad Central Hospital, and Microbiology department at faculty of medicine King Khalid Uni- 
versity for their kind technical assistance and collaboration.

\section{Conflict of Interest}

No conflict of interest associated with this work.

\section{Contribution of Authors}

The authors declare that this work was done by the authors named in this article and all liabilities pertaining to claims relating to the content of this article will be borne by them.

\section{References}

[1] WHO Report 2015.

[2] Alhajoj, S.A. (2010) Tuberculosis in Saudi Arabia. Journal of Infection and Public Health, 3, 17-24. https://doi.org/10.1016/j.jiph.2009.12.001

[3] Varghese, B., Supply, P., Shoukri, M., Allix-Beguec, C., Memish, Z., Abuljadayel, N., Alhakeem, R., Alrabiah, F. and Alhajoj, S. (2013) Tuberculosis Transmission among Immigrants and Autochthonous Populations of the Eastern Province of Saudi Arabia. PLoS ONE, 8, e77635. https://doi.org/10.1371/journal.pone.0077635

[4] Al-Orainey, I., Alhedaithy, M.A., Alanazi, A.R., Barry, M.A. and Almajid, F.M. (2013) Tuberculosis Incidence Trends in Saudi Arabia over 20 Years: 1991-2010. Annals of Thoracic Medicine, 8, 148-152. https://doi.org/10.4103/1817-1737.114303

[5] Eisenach, K.D., Cave, M.D. and Crawford, J.T. (1993) PCR Detection of Mycobacterium tuberculosis. In: Persing, D.H., Smith, T.F., Tenover, F.C. and White, T.J., Eds., Diagnostic Molecular Microbiology: Principles and Applications, American Society for Microbiology, Washington DC, 191-196.

[6] Noordhoek, G.T., Kolk, A.H., Bjune, G., Catty, D., Dale, J.W., Fine, P.E., Godfrey-Faussett, P., Cho, S.N., Shinnick, T., Svenson, S.B., et al. (1994) Sensitivity and Specificity of PCR for Detection of Mycobacterium tuberculosis: A Blind Comparison study among Seven Laboratories. Journal of Clinical Microbiology, 32, 277-284.

[7] Herrera, E.A., Perez, O. and Segovia, M. (1996) Differentiation between Mycobacterium tuberculosis and Mycobacterium bovis by a Multiplex-Polymerase Chain Reaction. Journal of Applied Bacteriology, 80, 596-604. https://doi.org/10.1111/j.1365-2672.1996.tb03263.x

[8] Hellyer, T.J., DesJardin, L.E., Assaf, M.K., et al. (1996) Specificity of IS6110-Based Amplification Assays for Mycobacterium tuberculosis Complex. Journal of Clinical Microbiology, 34, 2843-2846.

[9] Shawar, R.M., El-Zaatari, F., Nataraj, A. and Clarridge, J.E. (1993) Detection of Mycobacterium tuberculosis by Two-Step Polymerase Chain Reaction and Non Isotopic Hybridization Methods. Journal of Clinical Microbiology, 31, 61-65.

[10] Folgueira, L., Delgado, R., Palenque, E., Aguado, J.M. and Noriega, A. (1996) Rapid Diagnosis of Mycobacterium tuberculosis Bacteremia by PCR. Journal of Clinical Microbiology, 34, 512-515.

[11] Akcan, Y., Tuncer, S., Hayran, M., Sungur, A. and Unal, S. (1997) PCR on Disseminated Tuberculosis in Bone Marrow and Liver Biopsy Specimens: Correlation to Histopathological and Clinical Diagnosis. Scandinavian Journal of Infectious Diseases, 29, 271-274. https://doi.org/10.3109/00365549709019041

[12] Marchetti, G., Gori, A., Catozzi, L., Vago, L., Nebuloni, M., Rossi, M.C., Esposti, 
A.D., Bandera, A. and Franzetti, F. (1998) Evaluation of PCR in Detection of $M y-$ cobacterium tuberculosis from Formalin Fixed, Paraffin-Embedded Tissues: Comparison of Four Amplification Assays. Journal of Clinical Microbiology, 36, 15121517.

[13] Telenti, A., Marchesi, F., Balz, M., Bally, F., Bottger, E.C. and Bodmer, T. (1993) Rapid Identification of Mycobacteria to the Species Level by Polymerase Chain Reaction and Restriction Enzyme Analysis. Journal of Clinical Microbiology, 31, 175-178.

[14] Van Rie, A., Page-Shipp, L., Scott, L., Sanne, I., Stevens, W. (2010) Xpert ${ }^{\circledR}$ MTB/RIF for Point-of-Care Diagnosis of TB in High-HIV Burden, Resource-Limited Countries: Hype or Hope? Expert Review of Molecular Diagnostics, 10, 937-946. https://doi.org/10.1586/erm.10.67

[15] Helb, D., Jones, M., Story, E., Boehme, C., Wallace, E., Ho, K., Kop, J., Owens, M.R., Rodgers, R., Banada, P., et al. (2010) Rapid Detection of Mycobacterium tuberculosis and Rifampin Resistance by Use of On-Demand, Near-Patient Technology. Journal of Clinical Microbiology, 48, 229-237. https://doi.org/10.1128/JCM.01463-09

[16] Boehme, C.C., Nabeta, P., Hillemann, D., Nicol, M.P., Shenai, S., Krapp, F., Allen, J., Tahirli, R., Blakemore, R., Rustomjee, R., et al. (2010) Rapid Molecular Detection of Tuberculosis and Rifampin Resistance. New England Journal of Medicine, 363, 1005-1015. https://doi.org/10.1056/NEJMoa0907847

[17] Kent, P.T. and Kubica, G.P. (1985) Public Health Mycobacteriology: A Guide for the Level III Laboratory. Center for Disease Control, Atlanta.

[18] Doig, C., Seagar, A.L., Watt, B. and Forbes, K.J. (2002) The Efficacy of the Heat Killing of Mycobacterium tuberculosis. Journal of Clinical Pathology, 55, 778-779. https://doi.org/10.1136/jcp.55.10.778

[19] El-Dawi, T.G., Saeed, E.S. and Hamid, M.E. (2004) Evaluation of a PCR-Amplified IS6110 in the Rapid Diagnosis of Tuberculosis in Comparison to Smear Method. Saudi Medical Journal, 25, 1644-1647.

[20] Eisenach, K.D., Cave, M.D., Bates, J.H. and Crawford, J.T. (1990) Polymerase Chain Reaction Amplification of a Repetitive DNA Sequence Specific for Mycobacterium tuberculosis. Journal of Infectious Diseases, 161, 977-981. https://doi.org/10.1093/infdis/161.5.977

[21] Neonakis, I.K., Gitti, Z., Krambovitis, E., and Spandidos, D.A. (2008) Molecular Diagnostic Tools in Mycobacteriology. Journal of Microbiological Methods, 75, 111. https://doi.org/10.1016/j.mimet.2008.05.023

[22] Macente, S., Leite, C., Santos, A., Sequeira, V., Machado, L., Marcodens, N., Herata, M., Herata, R. and Cardoso, R. (2013) Evaluation of Hsp65 Nested PCR-Restriction Analysis (PRA) for Diagnosing of Tuberculosis in High Burden Country. BioMed Research Journal, 2013, Article ID: 391549.

[23] Ritis, K., Tzoanopoulos, D., Speletas, M., Papadopoulos, E., Arvanitidis, K., Kartali, S. and Sideras, P. (2000) Amplification of IS6110 Sequence for Detection of M. tuberculosis Complex in HIV-Negative Patients with FUO and Evidence of Extra-Pulmonary Disease. Journal of Internal Medicine, 248, 415-424. https://doi.org/10.1046/j.1365-2796.2000.00750.x

[24] Patel, V., Connolly, C., Singh, R., Lenders, L., Matinyenya, B., Theron, G., Ndungu, T. and Dheda, K. (2014) Comparison of Amolicor and GeneXpert MTP/RIF for Diagnosis of Tuberculous Meningitis. Journal of Clinical Microbiology, 52, 37773780. https://doi.org/10.1128/JCM.01235-14

[25] Theron, G., Venter, R., Calligaro, G., Smith, L., Limberis, J., Meldau, R., Chanda, D., 
Esmail, A., Peter, J. and Dheda, K. (2016) Xpert MTB/RIF Results in Patients with Previous Tuberculosis: Can We Distinguish True from False Positive Results? Clinical Infectious Diseases, 62, 995-1001. https://doi.org/10.1093/cid/civ1223

Submit or recommend next manuscript to SCIRP and we will provide best service for you:

Accepting pre-submission inquiries through Email, Facebook, LinkedIn, Twitter, etc. A wide selection of journals (inclusive of 9 subjects, more than 200 journals)

Providing 24-hour high-quality service

User-friendly online submission system

Fair and swift peer-review system

Efficient typesetting and proofreading procedure

Display of the result of downloads and visits, as well as the number of cited articles

Maximum dissemination of your research work

Submit your manuscript at: http://papersubmission.scirp.org/

Or contact jtr@scirp.org 